1. Steere AC. Lyme Disease. N Engl J Med 1989, 321: 586-596.

2. Williams AE, Bergl S, Twycross RG. A 5-year review of a lymphoedema service. Eur J Cancer Care 1996; 5(1): 56-59.

3. Steere AC, Bartenhagen NJ, Craft JE, et al. The early clinical manifestations of Lyme disease. Ann Intern Med 1983; 99: 76-82.

4. Duffy J. Lyme Disease. Ann Allergy 1990; 65: 1-13

5. Fritschi J. Der Fall aus der Ptaxis (128). Patient: Herr BL, geb. 1947, Ingenieur. Schweiz Rundsch Med Prax 1981; 78(4): 74-75.

6. Budmiger $\mathrm{H}$. et al. Beinschwellung, Hautatrophie. Schweiz Rundsch Med Prax 1987; 76(16): 32-35.

\section{Quemaduras en la mucosa oral y erosiones cutáneas}

\section{Sr. Director:}

El término pénfigo se refiere a un grupo de enfermedades ampollosas autoinmunes de la piel y mucosas, caracterizadas histológicamente por ampollas intraepidérmicas debidas a acantolisis e inmunopatológicamente por el depósito de IgG e IgG circulante dirigida contra la superficie celular de los queratinocitos (1). Se distinguen dos tipos mayores de pénfigo: vulgaris, en el que las ampollas están en la parte más profunda de la epidermis, sobre la membrana basal y foliáceo, con ampollas más superficiales en la capa granulosa. Recientemente se describió el pénfigo paraneoplásico con características clínicas e histopatológicas únicas. El pénfigo es una enfermedad poco frecuente, tanto para el médico de atención primaria como para el internista, lo que dificulta su diagnóstico.

Presentamos el caso de una mujer de 70 años que consultó porque unos tres meses antes del ingreso comenzó con molestias en orofaringe, por lo que hizo enjuagues bucales con alcohol de $96^{\circ}$ en varias ocasiones, apareciendo posteriormente úlceras en la mucosa oral muy dolorosas, con hipersalivación continua y que finalmente le impedían la ingesta. Un mes después se añadieron lesiones cutáneas erosivas y pérdida de $20 \mathrm{~kg}$ de peso en este tiempo. En la exploración física destacaban erosiones en la mucosa oral, lengua y paladar con hipersialorrea y en la piel erosiones de $2 \times 3 \mathrm{~cm}$, no confluyentes, de distribución predominante en tronco y extremidades superiores, con signo de Nikolsky positivo. Las exploraciones complementarias básicas incluído hemograma, velocidad de sedimentación globular (VSG), bioquimica, coagulación, proteinograma y radiograffa de tórax eran normales. Se realizó un cultivo de exudado faringo-amigdalar que fue negativo. En la endoscopia digestiva alta se apreciaban lesiones erosivas en la mucosa oral, lingual y faríngea, con sobreinfección candidiásica y en esófago dos pequeñas lesiones mucosas vesiculares con signo de Nikolski positivo. La biopsia de piel realizada demostró zonas de acantolisis, con ampollas intraepidérmicas justo por encima de la capa basal. En la inmunofluorescencia se vio la presencia de depósitos a nivel de la epidermis entre los queratinocitos positivos para IgG y C3, diagnosticándose a la paciente de pénfigo vulgar.

En la mayoría de pacientes el signo de presentación del pénfigo son erosiones mucosas tremendamente dolorosas, precediendo incluso en meses a las lesiones cutáneas, como en nuestro caso (2). Otras enfermedades que pueden cursar con lesiones erosivas en cavidad oral, y con las que hay que hacer el diagnóstico diferencial son, otras enfermedades ampollosas autoinmunes, estomatitis gingival herpética, estomatitis micótica, estomatitis química, estomatitis acompañando a colagenosis, liquen plano y tumores (3). En nuestra paciente coexistía afectación oral por pénfigo, además de estomatitis química inducida por el alcohol y sobreinfección candidiásica. La afectación esofágica parece relativamente común según se desprende de una serie publicada de 25 pacientes con pénfigo vulgaris, en la cual 18 (72\%) tenían afectación esofágica en la endoscopia (4). De todas formas ésta es la única serie publicada en la que se valora dicha afectación, correspondiendo el resto de publicaciones a algún caso aislado (5).

En el pénfigo vulgar los anticuerpos $\mathrm{IgG}$ van dirigidos contra desmogleína 3 en los desmosomas de la piel y mucosas. Aunque la presencia de estos autoanticuerpos puede ser de ayuda en el diagnóstico y seguimiento de la actividad de la enfermedad, el diagnóstico definitivo viene dado por la biopsia de piel y/o mucosas y para el seguimiento resulta más útil basarse en la clínica que en el título de anticuerpos (6)

El pénfigo vulgar es una enfermedad mortal sin tratamiento. La introducción de glucocorticoides sistémicos y posteriormente inmunosupresores ha mejorado claramente el pronóstico de estos enfermos, pero todavía es una enfermedad no exenta de morbimortalidad sobre todo por las complicaciones derivadas del tratamiento. Ha habido controversia sobre el tratamiento con esteroides a dosis altas (> $100 \mathrm{mg} / \mathrm{d})$ o intermedias. La tendencia actual es usar esteroides a dosis intermedias y añadir inmunosupresores, lo que permite el control de la enfermedad con disminución importante de los efectos secundarios relacionados con el tratamiento. Es muy importante la monitorización de posibles efectos adversos relacionados con la medicación. En nuestra paciente se inició tratamiento con prednisona $(90 \mathrm{mg} /$ día $)$ y un mes después se inició descenso de la dosis de esteroides comenzando con azatioprina $(50 \mathrm{mg} /$ día $)$ evolucionando la enferma de forma lenta pero favorable.

\section{E. Ameneiros Lago, A. Mariño Callejo, A. Echarri Piudo, P. Sesma Sánchez}

Servicio de Medicina Interna y Digestivo. Hospital Arquitecto Marcide. Ferrol. La Coruña

1. Stanley JR. Phemphigus. En: Fitzpatrick TB et al. (eds): Dermatology in General Medicine 4a th. New York, McGraw-Hill 1993; 606-614.

2. Rye B, Webb JM. Autoinmune bullous diseases. Am Fam Physician 1997; 55 (8): 2709-18.

3. Ishii T, Furusawa S, Iguti Y, Kuno T, Nishiyama K, Yamamoto K et al One case of phemphigus vulgaris observed in the oral cavity. Acta Otolaryngol (stocckh) 1996; Suppl 524: 73-78.

4. Deo\&ar KP. Esophageal involvement in phemphigus vulgaris. Indian J Gastroenterol 1994; 13 (4): 133-134.

5. Amichai B, Grumwald MH, Gasper N, Finkelstein E, Halevy S. A case of phemphigus vulgaris with esophageal involvement. J Dermatol 1996; 23 (3): 214-215

6. Thivolet J. Phemphigus: past, present and future. Dermatology 1994; Suppl 189: 26-29.

\section{Bacteriemia por Flavimonas oryzihabitans en un paciente no neutropénico con enfermedad cardiaca}

\section{Sr. Director:}

Flavimonas oryzihabitans, antes conocido como Pseudomo nas oryzihabitans, CDC grupo Ve 2 o Chromobactertum typhi flavum, es un bacilo gram negativo, no fermentador, que presenta un color amarillo característico (1). Se trata de una bacteria frecuentemente recuperada de ambientes tales como plantaciones de arroz, suelos y agua estancada; sin embargo, también se encuentra en el ámbito hospitalario (lavabos, equipos de inhalación y otras superficies ambientales) (2). Flavimonas oryzihabitans raramente causa infecciones en humanos y en muy pocos casos estas infecciones son clínicamente significativas. Estas últimas 